\title{
REDES METROPOLITANAS BRASILEIRAS E O AUMENTO DA (IN)GOVERNANÇA URBANA
}

\author{
BRAZILIAN METROPOLITAN NETWORKS, AND THE \\ INCREASING OF THE URBAN (IN)GOVERNANCE
}

\author{
A. Leonardo de Souza Polli \& B. Júlia O. R. Cerqueira \& C. \\ Lorenna Lemos Cardoso \\ Urbanismo; Universidade do Estado da Bahia, Brasil \\ Ipolli@uneb.br \\ julia.jorc@gmail.com \\ lorennacardoso97@gmail.com
}

\begin{abstract}
RESUMO
Esse artigo é o resultado das interações intelectuais entre professor e estudantes do curso de Urbanismo da Universidade do Estado da Bahia, tendo sido consolidado a partir de uma metodologia investigativa desenvolvida em pesquisas e debates sobre a gestão urbana nas cidades brasileiras, e a visualização e interpretação de dados, reforçados com instrumentos de percepção espacial e de geoprocessamento, que potencializou a investigação. Nesse sentido, abordar-se-á nesse ensaio o que denominamos de "limites da (in)governança urbana no Brasil", em ordem a iniciar apresentando notas e entendimentos sobre o processo global de metropolização, em seguida, apresentar observações sobre o processo de maturação de nossa legislação urbana e metropolitana. Por fim, traz-se as conclusões finais ancoradas em conceitos epistemológicos sobre a palavra "limite", apresentando considerações a respeito dos limites observados na lei do Estatuto das Metrópoles, a considerar os: i) limites escalares; ii) limites políticos-administrativos; iii) limites econômicos-sociais; e iv) limites referenciais.
\end{abstract}

Palavras chave: Limites, Regiões Metropolitanas, Estatuto da Metrópole.

Linha de Investigação: 1. Cidade e Projeto

Tópico: Estudos metropolitanos e territoriais

\begin{abstract}
This article is the result of intellectual interactions between professor and students of the Urbanism course at the University of the State of Bahia, having been consolidated from an investigative methodology developed in research and debates on urban management in Brazilian cities, and the visualization and interpretation of data, reinforced with spatial perception and geoprocessing instruments, which enhanced the investigation. In this context, this essay will address what we call "limits of urban (in) governance in Brazil", in order to start the notes and understandings about the global process of metropolization, then present about the maturation process of our urban and metropolitan legislation. Finally, it brings as final rights anchored in epistemological concepts about the word "limit", considerations regarding the limits observed in the law of the Statute of the
\end{abstract}




\section{SÃOPAULO15 - $17 \cdot$ LISBOA $25 \sim 26$ JUN 2020}

Metropolises, to consider the: i) scalar limits; ii) political and administrative limits; iii) social and economic limits; and iv) reference limits.

Keywords: Limits, Metropolitan Regions, Metropolis Statute.

Thematic cluster: 1 . City and Project.

Topic: Metropolitan and territorial studies

\section{Tendências globais do processo de urbanização e formação de redes metropolitanas (tanto em escala, quanto em função)}

Avançar na compreensão sobre as mudanças históricas no papel dos governos é condição importante para identificar os fatores que contribuíram para a emergência e necessidade de modernização e instrumentalização da política urbana enquanto campo de gestão, planejamento e intervenção do Estado sobre o espaço. Essa compreensão permite constatar, por exemplo, que a internacionalização econômica, conhecida por globalização, ocorrida essencialmente a partir da década 1970, e ampliada desde então, inaugurou uma nova tendência do capitalismo que desencadeou reformas políticas, administrativas e gestoras descentralizadoras pelo mundo.

Desde então, a formação de grandes áreas e redes urbanas, de limites geográficos, demográficos, sociais e econômicos pouco precisos, que se desenvolvem a partir de polos metropolitanos, representa um dos aspectos relevantes nessa descentralizadora tendência de planejamento e organização contemporânea do espaço. Sendo assim, analisar esses movimentos metropolitanos é aventar uma série de relações e análises que são superiores à ideia tradicional do modelo industriário-fordista de reconhecer os centros urbanos apenas como um fenômeno de crescimento das grandes aglomerações e concentrações industriarias e demográficas. (Soares, 2018)

No atual período, em que a mundialização atinge patamares sem precedentes históricos e as grandes cidades e regiões metropolitanas, por consequência, são projetadas como plataformas dos capitais nacional e internacional, observam-se modificações de forma e conteúdo dessas paisagens, que acabam por exigir uma organização de planejamento e gestão contextualizada em face às atuais necessidades e problemáticas. Pierre Veltz, em sua importante obra "Mundialização, cidades e territórios" ( Veltz, 1999: 9), apontou o que ele considerou os três grandes processos da economia mundial no final do século XX: (I) a mundialização e a globalização da economia; (II) a transformação dos modos de organização e funcionamento das empresas e da produção; e (III) a concentração territorial crescente da economia nas metrópoles, que, dialeticamente, carrega consigo o crescimento das desigualdades territoriais em uma nova escala.

A metrópole contemporânea do século XXI se tornou, essencialmente, um espaço de serviços altamente especializados, tanto para as pessoas, quanto para as atividades industriais e empresariais. De fato, trata-se aqui de um espaço funcional para a gestão da economia capitalista global, ao passo que o mesmo também se torna funcional para os fluxos, demandas e concentrações sociais. Esse grau de complexidade exige uma nova e maior racionalidade na gestão por parte das empresas e governos (Sassen, 1998).

Por se tratar, portanto, de uma nova fase histórica de concentração urbana, nesse ensaio consideramos que consolidou-se um processo em rede de temáticas (e problemáticas) extremamente complexas, como: a) a 


\section{SÃO PAULO15 17 LISBOA $25 \sim 26$ JUN 2020

formação de uma região urbana brasileira com ampla escala territorial; b) a constituição de regiões que tendem à homogeneidade, sendo hierarquizadas pela cidade-polo metropolitana; c) o aumento dos fluxos de pessoas e materiais intra e inter metropolitanos; d) o aumento territorial (escalar) das desigualdades sociais e econômicas. Em resumo, acredita-se que a segregação socioespacial das grandes cidades se expande para o contexto metropolitano. Nesse sentido, observa-se, por exemplo, que problemáticas relacionadas à questão da mobilidade urbana não são mais perceptíveis apenas em uma cidade específica, mas em toda a rede relacional entre municípios.

Diante desse cenário, a complexidade das mudanças econômicas, sociais, políticas e culturais no mundo atual tem um referencial importante na produção, organização e planejamento do espaço. Nesse sentido, as contradições e segregações sociais e econômicas, e as próprias dinâmicas espaciais promovidas pelos agentes que produzem o espaço urbano (Corrêa, 1989), acabam por nortear - e foi assim ao longo da história moderna das cidades -, todo um conjunto de ações e políticas públicas que visam mediar a ação dos agentes formadores do espaço, controlando suas atividades, interesses e usos territoriais.

Mundialmente, exemplos significativos de ação governamental no ordenamento territorial servem como base e modelo para a tentativa de se construir uma justiça urbana e social. Evidentemente, cada caso demonstra uma perspectiva diferente de ação política e territorial, mas o que unifica as ações eficientes e eficazes é a tentativa de se equalizar interesses diversos, e as inevitáveis contradições sociais, econômicos, gestoras e ambientais em grandes e densos perímetros urbanos. Estudar exemplos internacionais implica, também, correlacionar as mudanças significativas no funcionamento cotidiano das aglomerações, e a constituição de novos tipos de morfologias e relações urbanas e regionais (Ascher, 2010: 80).

Atendo-se ao caso brasileiro - recorte desse trabalho -, pode-se observar que esses conceitos e referências começam a ser colocados em prática, e com certo atraso, a partir do processo de redemocratização brasileira consolidado com a Carta Magna de 1988, especificamente com uma série de instrumentos legais que consolidaram o propósito de descentralizações administrativa, financeira, gestora, política e territorial do país. Sob a ótica das cidades, a Lei Federal $n^{\circ} 10.257 / 2001$, conhecida como Estatuto da Cidade (EC), representa um considerável avanço em toda essa norteadora política decentralizada de planejamento e intervenção nos municípios do país, orientando o poder público a uma agenda comum de gestão, tendo como base princípios fundamentais estabelecidos pela referida lei ${ }^{1}$.

Todavia, apesar dos inegáveis avanços, cabe ressaltar que o atraso dessas políticas é algo significativo diante de um dos países que mais rapidamente se urbanizou em todo o mundo. $O$ acelerado processo de transformação do habitat e da sociedade brasileira produziu uma urbanização predatória, desigual e, sobretudo, iníqua. Diante disso, pode-se dizer que o próprio EC já nasce com muitas atribuições, demandas e expectativas históricas e contemporâneas, em um cenário onde existe uma real dificuldade para equalizar e equilibrar o urbano, para todos os diversos agentes e interesses abruptamente consolidados.

Não obstante essa realidade, o já mencionado processo tendencial de metropolização e complexidade urbana coloca o EC, no mínimo, em defasagem diante da complexa realidade contemporânea. Abordar dessa forma essa importante lei, diante de uma histórica realidade nacional onde poucas foram construídas com tanto esforço técnico-coletivo e legitimidade social, parece um equívoco, mas não o é. Inegavelmente,

\footnotetext{
${ }^{1}$ A considerar, segundo a Lei Federal 10.257/2001: i) gestão democrática; ii) justa distribuição dos ônus e benefícios decorrentes do processo de urbanização; iii) a recuperação dos investimentos do poder público que tenham resultado em valorização de imóveis urbanos; e o iv) direito a cidades sustentáveis, à moradia, à infraestrutura urbana e aos serviços públicos. Disponível em http://www.planalto.gov.br/ccivil_03/LEIS/LEIS_2001/L10257.htm, acessado em: 03/02/2020.
} 


\section{SÃOPAULO15 17 LISBOA $25 \sim 26$ JUN 2020

ao passo que as metrópoles consolidam o seu desenvolvimento tendencial, e estabelecem suas redes e problemáticas intra e inter urbanas, os instrumentos previstos pelo Estatuto da Cidade ainda estão sendo, a duras realidades observadas, adotados. Nesse sentido, se observa ainda processos e disputas políticas locais que acabam por atrasar a efetivação de políticas e estratégias de governança e governabilidade espacial, que reconheça a diversidade multiterritorial e em redes do território brasileiro.

A contradição observada no conjunto jurídico das legislações urbanas é tão objetiva que, mesmo com a aprovação da Política Nacional de Ordenamento Territorial em 2007 - hierarquizada a partir do Governo Federal -, não houve uma integração territorial efetiva entre os municípios e regiões e, sendo assim, essa política acabou por contribuir muito pouco com um fortalecimento em redes interurbanas. Já em 2015, reconhecendo as complexas relações interurbanas, e tentando preencher as lacunas de planejamento e gestão em áreas metropolitanas, uma nova lei de impactos tão similares quanto o EC é aprovada, com efetivações práticas ainda pouco mensuradas e analisadas até então. Refere-se aqui a Lei Federal $n^{\circ}$ 13.089/2015, o Estatuto da Metrópole (EM). Esse novo Estatuto determina diretrizes gerais para o planejamento, a gestão e a execução das Funções Públicas de Interesse Comum (FPIC) entre os municípios pertencentes a regiões metropolitanas, ou em aglomerações urbanas instituídas pelos Estados. Para além, visa estabelecer também normas gerais sobre o Plano de Desenvolvimento Urbano Integrado e outros instrumentos de governança Inter federativa, compartilhando responsabilidades e ações entre os entes da federação em relação à organização, o planejamento e à execução das FPIC.

Ou seja, diante de barreiras reais de aplicar os instrumentos do EC, objetivou-se consolidar uma rede metropolitana de Governança e Governabilidade que se propõe a organizar, planejar e gerenciar um território que, do ponto de vista escalar, promove muito mais complexidades espaciais, econômicas, sociais, ambientais etc. Dessa inquietação, surgiu a problemática e, por consequência, toda uma perspectiva de produção reflexiva entre os autores desse trabalho, que visa percorrer um caminho investigativo sobre os reais limites e problemas da efetivação de uma política de democracia e justiça espacial brasileira, agora em escala metropolitana.

Não obstante, compete aqui mencionar que ainda tateia-se coletivamente sobre a eficiência e aplicabilidade real de conteúdos voltados para o estímulo a informação, organização, participação e aplicação da pauta social. Em verdade, não são incomuns casos que reforçam, em conteúdo, uma pressão privatista às cidades, mesmo dispondo, em formas, de processos ditos participativos e com envolvimento social.

\section{Um país "metropolitano", uma realidade complexa}

Diante da fundamentação inicial, compete apresentar de maneira delimitada o objeto de estudo dessa análise e, por consequência, uma breve contextualização do Estatuto da Metrópole que sustenta esse material. Inicialmente, cabe ressaltar que as delimitações das chamadas regiões metropolitanas no Brasil iniciaram nos anos 1960, tendo como base um estudo realizado pelo Instituto Brasileiro de Geografia e Estatística (IBGE). Diante desse estudo, e já na década de 1970, foram instituídas as nove primeiras Regiões Metropolitanas do Brasil, sendo que a Lei Complementar ํo. 14/1973 criou as oito primeiras regiões metropolitanas brasileiras, a constar: São Paulo (SP); Belo Horizonte (MG), Porto Alegre (RS), Curitiba (PR); Salvador (BA); Recife (PE); Fortaleza (CE); e Belém (PA) e, no ano seguinte, a Região Metropolitana do Rio de Janeiro foi instituída pela Lei Complementar nํ.. 20/1974. 


\section{SÃO PAULO15 17 LISBOA $25 \sim 26$ JUN 2020

Com o processo de redemocratização brasileira, e toda a descentralização e compartilhamento das atividades políticas e administrativas entre os entes federados, passa a competir aos Estados a responsabilidade de estabelecer a rede metropolitana de municípios, bem como instituir aglomerações urbanas e microrregiões de desenvolvimento integrado em seus territórios, visando sempre fortalecer uma relação em redes entre municípios limítrofes, com o objetivo de integrar a organização, o planejamento e a execução de funções públicas de interesse comum. Diante dessa política descentralizada (mantida com a criação do EM, em 2015), registra-se que, entre o final da década de 1980 até o ano de 2010, foram criadas 27 Regiões Metropolitanas (RM) e três Regiões Integradas de Desenvolvimento (RIDE). Depois de 2010, o número vem sendo modificado constantemente. Segundo levantamentos realizados no próprio IBGE, há uma proliferação das RM's nos Estados, e, ainda em 2015, (antes mesmo da aprovação do EM) já somavam 73 RM's. Atualmente, após a aprovação do EM, os números são ainda mais altos. Registra-se no país um total de 74 Regiões Metropolitanas (sendo 24 envolvendo captais estaduais), seis RIDE's e ainda cinco Aglomerações Urbanas (AU).

Acredita-se ser aqui fundamental estabelecer os conceitos adotados pelo IBGE em relação a essas estruturas de organização territorial desenvolvidas no Brasil, que são semestralmente aplicados na Pesquisa de Regiões Metropolitanas, Aglomerações Urbanas e Regiões Integradas de Desenvolvimento e que sustentam essa produção do ponto de vista qualiquantitativo. Segundo o instituto:

As Regiões Metropolitanas e Aglomerações Urbanas são constituídas por agrupamentos de municípios limítrofes e são instituídas por lei complementar estadual, de acordo com a determinação do artigo 25 , parágrafo $3^{\circ}$ da Constituição Federal de 1988, visando integrar a organização, o planejamento e a execução de funções públicas de interesse comum. Na listagem disponibilizada pelo IBGE constam também categorias associadas a esses recortes: colares metropolitanos, arcos metropolitanos, áreas de expansão metropolitana, subdivisões metropolitanas, dentre outras. As Regiões Integradas de Desenvolvimento, por sua vez, são definidas como regiões administrativas que abrangem diferentes unidades da federação. Esses recortes são criados por legislação específica, na qual as unidades da federação que as compõem são elencadas, além de definir a estrutura de funcionamento $e$ os interesses das unidades político-administrativas participantes. No caso das RIDEs, a competência de criá-las é da União, com base nos artigos 21, inciso IX; 43 e 48, inciso IV, da Constituição Federal (Idem, 2019).

Ainda no debate sobre as tendências metropolitanas, compete destacar que, segundo o IBGE, o Brasil possui atualmente 5.570 municípios, e a partir de toda uma pesquisa envolvendo as bases de informação geográfica do instituto, foi capaz de perceber que, desse total, 1.421 são pertencentes a RM's, RIDE's ou AU's, representando cerca de $25 \%$ de todas as cidades brasileiras. A realidade é incontestável, e o país apresenta-se com uma exponencial tendência metropolitana. Parece óbvio chegar a essa conclusão, mas para tornar mais evidente ainda, competiu a esses pesquisadores apresentar um mapa geral da realidade urbana brasileira, objetivando desenvolver conclusões mais objetivas sobre esse processo.

Estabelecer uma pesquisa que vise analisar um quarto dos municípios brasileiros não se apresenta como uma tarefa fácil. Todavia, cabe refletir sobre a ideia de que, concomitantemente ao processo de metropolização brasileiro (e todas as dificuldades de interpretar esse fenômeno), algumas metodologias, conceitos e técnicas de percepção e representação do espaço também foram aprimoradas, colocando em 


\section{SÃOPAULO15 $17 \cdot$ LISBOA $25 \sim 26$ JUN 2020}

um patamar superior as possibilidades de pesquisa, investigação, e interpretação espacial. Para exemplificar esse patamar superior, apresenta-se o "objeto de pesquisa" no mapa a seguir (Fig. 01), produzida a partir da base de dados do IBGE (2019), e de todo um Sistema de Informações Geográficas (SIG), disponível para a manipulação e interpretação da informação de dados espaciais, por meio de uma ferramentas que possibilitou a sua visualização espacial no QGis (QGIS é um software livre com código-fonte aberto, multiplataforma de sistema de informação geográfica que permite a visualização, edição e análise de dados georreferenciados).

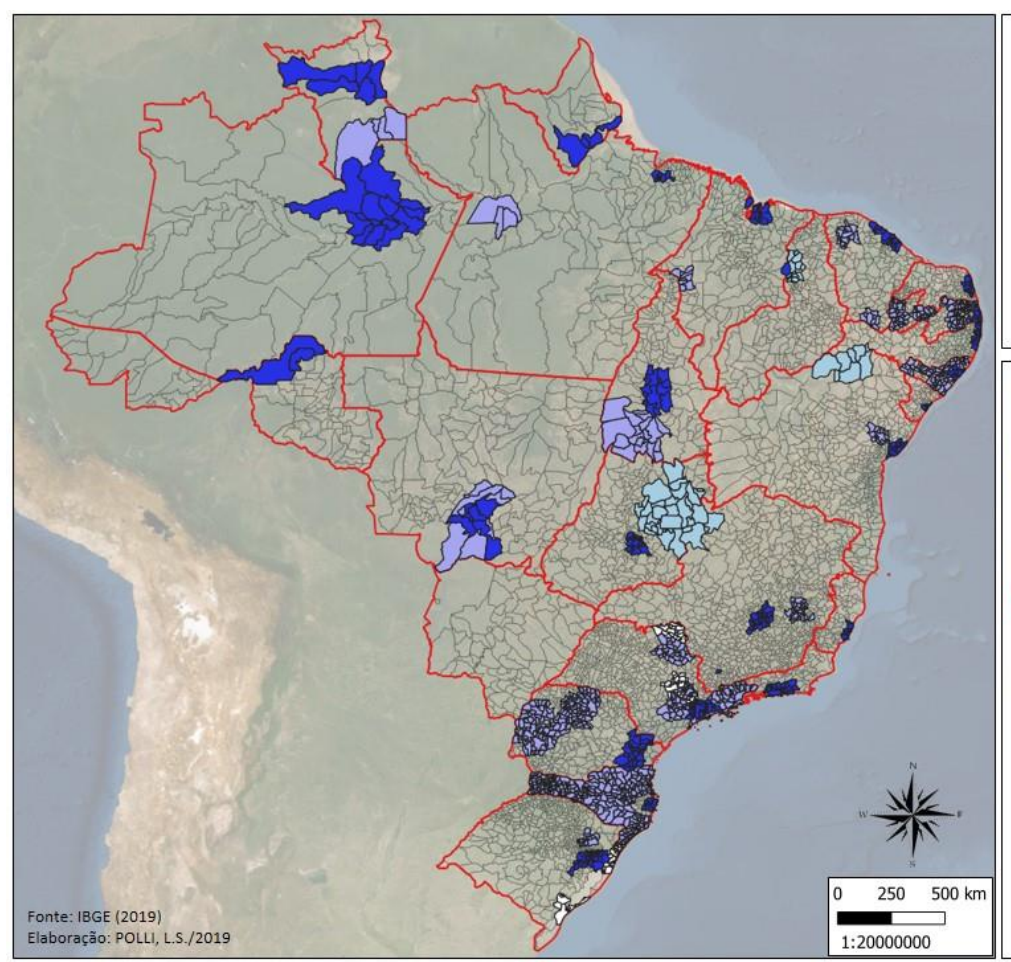

\section{MUNICÍPIOS BRASILEIROS EM REGIÕES METROPOLITANAS, REGIÕES INTEGRADAS DE DESENVOLVIMENTO OU AGLOMERAÇÕES URBANAS.}

\begin{tabular}{|l}
\hline LEGENDA \\
Regiões Metropolitanas envolvendo Capitais Estaduais \\
$\square$ Municípios em Regiões Metropolitanas \\
$\square$ Municípios em Aglomera ções Urbanas \\
$\square$ Municípios em Regiões Integradas de Desenvolvimento \\
$\square$ Limites Estaduais \\
Limites Municipais \\
Base da Imagem - Google Earth \\
INFORMAÇÕES ADICIONAIS \\
- Total de Regiões Metropolitanas: 74 \\
- Total de Regiões Integradas de Desenvolvimento: 6 \\
- Total de Aglomerações Urbanas: 5 \\
- Quantidade de Municípios no Brasil: 5.570 \\
- Quantidade de Municípios Metropolitanos: 1.421 \\
Porcentagem de Municípios Metropolitanos: $25 \%$ (Aprox.)
\end{tabular}

Fig. 01 Mapa do Brasil por municípios, Regiões Metropolitanas e Afins. Elaboração própria a partir de dados do IBGE (2019).

Certamente o mapa amplia o campo de percepção sobre o tema, e permite a observação de algumas contradições desse cenário. Primeiramente, compete destacar que as aglomerações metropolitanas revelam que há uma densidade populacional extremamente consolidada no Brasil, em uma porção territorial que representa cerca de um quarto do território nacional. Cerca de $80 \%$ da população brasileira (160 milhões de habitantes) reside nos municípios em destaque na Fig. 1. Evidentemente, esse dado revela que há uma densidade muita alta nas cidades e, naturalmente, esse "inchaço" urbano é perceptível em uma rápida observação sobre os parâmetros de ocupação e os níveis de problemas das grandes e médias cidades brasileiras.

Percebe-se que existem alguns conceitos estranhos de se observarem. Em particular, chama a atenção o estado de Santa Catarina, que possui quase que a totalidade dos municípios do estado pertencentes a regiões metropolitanas. Cabe mencionar, também, que apesar de não ser reconhecido como método territorial oficial adotado no Brasil, o Estado da Bahia - que possui apenas a Região Metropolitana de 


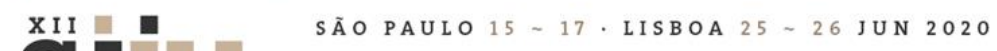

Salvador, a Região Metropolitana de Feira de Santana e a Região Integrada de Desenvolvimento JuazeiroPetrolina -, organiza-se territorialmente a partir dos chamados "Territórios de Identidade" (Fig. 2), adotado a partir de lei estadual específica, com o objetivo de identificar prioridades temáticas definidas a partir da realidade local, possibilitando o desenvolvimento equilibrado e sustentável entre as regiões. Nesse sentido, compete dizer que o Governo da Bahia passou a reconhecer a existência de 27 Territórios de Identidade, constituídos a partir da especificidade de cada região. Sua metodologia foi desenvolvida com base no sentimento de pertencimento, onde as comunidades, através de suas representações, foram convidadas a opinar. (Seplan, 2018).

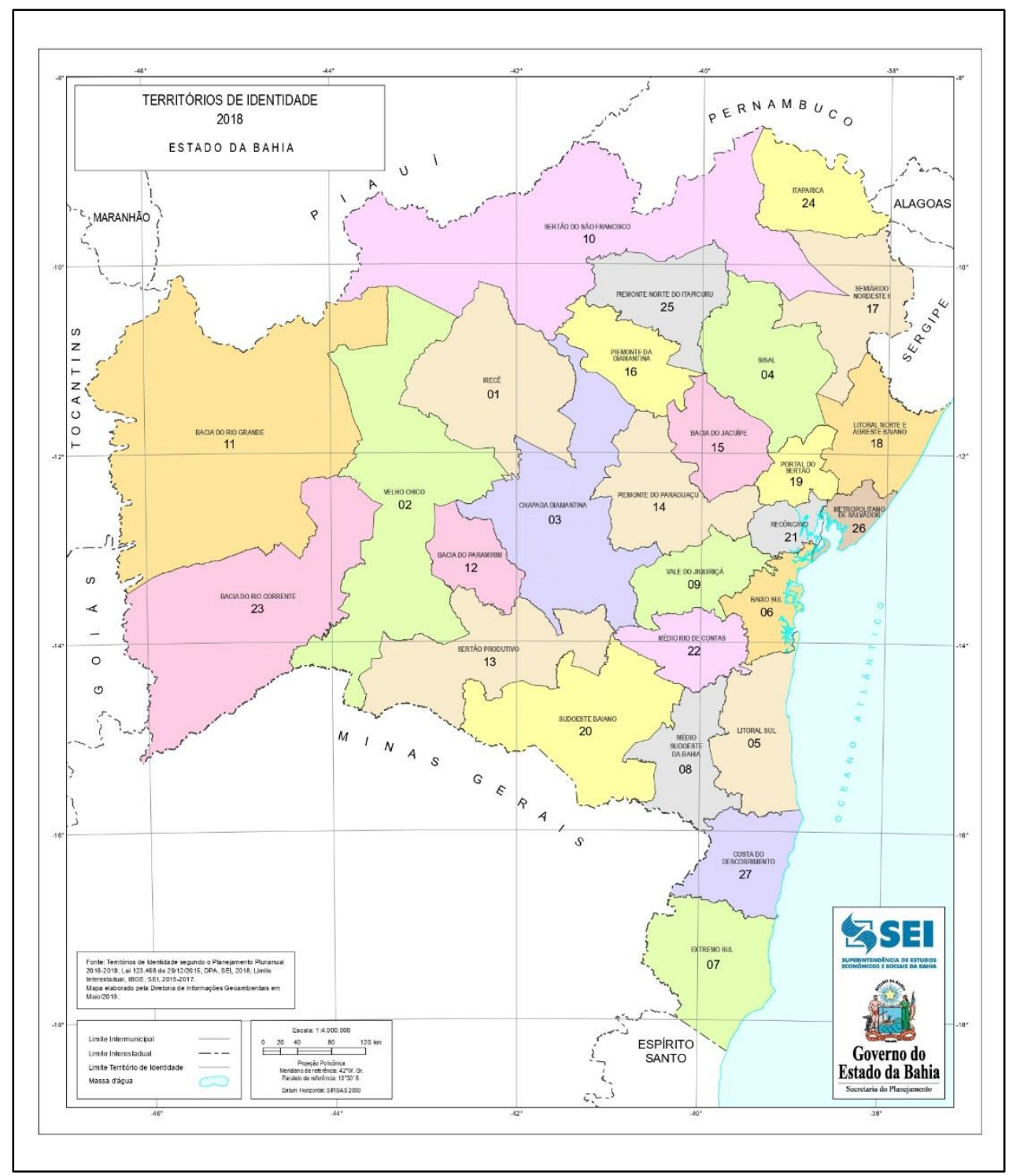

Fig. 02 Mapa dos territórios de identidade do Estado da Bahia. Superintendência de Estudos Econômicos e Sociais da Bahia - SEI (2018). 
Ou seja, exemplos - de diferentes ordens - observados em Santa Catarina e Bahia revelam que não há um entendimento global sobre o que seria uma região, ou rede, metropolitana. Mesmo com um referencial conceitual adotado pelo IBGE, as atribuições são desenvolvidas pelos estados em relação às definições territoriais. E daí incide a primeira inquietação do Estatuto das Metrópoles: para quem se direciona o estatuto? Essa pergunta parece óbvia, mas não é. O Brasil é, de fato, um país metropolitano (e com tendências de metropolização), entretanto, a realidade é mais complexa. E tentar responder a mesma, significa demonstrar com, na prática, as diferenças regionais e os interesses territoriais e políticos não se submetem a um único escopo metodológico de planejamento e desenvolvimento territorial e integrado. $O$ Estatuto já nasce com uma objeção conceitual e prática.

\section{Notas sobre o Estatuto da Metrópole}

Como abordado anteriormente, o Estatuto da Metrópole visa determinas diretrizes gerais para o planejamento, a gestão e a execução das Funções Públicas de Interesse Comum (FPIC) entre os municípios pertencentes a regiões metropolitanas, ou em aglomerações urbanas instituídas pelos Estados. Para além, visa estabelecer também normas gerais sobre o Plano de Desenvolvimento Urbano Integrado e outros instrumentos de governança interfederativa, compartilhando responsabilidades e ações entre os entes da federação em relação à organização, ao planejamento e à execução das FPIC.

Cabe afirmar que o EM trabalha com importantes conceitos que se relacionam, do ponto de vista conceitual, com uma real necessidade para as áreas metropolitanas no Brasil. Primeiramente, a ideia de Funções Públicas de Interesse Comum (FPIC). Nesse pensamento, se efetiva um entendimento prático relacionado ao fato de que não há rupturas física, ambiental e geográfica entre os municípios. Na verdade, os limites administrativos não passam de tratados e acordos, mas que há um interesse comum nessa continuidade geográfica. E, para isso, o EM introduz e determina outros necessários conceitos, a considerar a Governança interfederativa (estabelecendo, estimulando e promovendo uma gestão compartilhada dos objetivos e compromisso comuns), além da criação de um instrumento capaz de organizar todos os compromissos e objetivos, nomeado de Plano de Desenvolvimento Urbano Integrado (PDUI).

Ou seja, todos os conceitos elencados no EM referem-se ao que define por gestão interfederativa das funções públicas de interesse comum. Entende-se diretamente, então, que o objetivo maior desta lei é garantir a prestação de serviços públicos essenciais de forma integrada aos munícipios, nas abrangências da região metropolitana, uma vez que, devido à expansão destes, sua disposição interfere e influencia a dinâmica de municípios limítrofes, e em situações mais "críticas", leva a conurbação de escala, e de problemas.

Já o segundo capítulo desta lei prevê que, além de serem criadas por lei complementar pelos estados, os PDUI só poderão ser concretizados após a realização de estudos técnicos e audiências públicas. Estabelece, também, que regiões que contemplem mais de um estado (caso das RIDE's) só serão formalizadas mediante a aprovação de leis complementares pelas assembleias legislativas de cada um dos Estados envolvidos. Já abordamos sobre a complexidade do cenário metropolitano brasileiro, e isso certamente se soma ao processo de gestão e governança metropolitanas. Ora, o que ocorre na prática, senão a condução de interesses políticos, econômicos e sociais próprios? Afinal, compartilhar supostos benefícios adventos de uma gestão interfederativa é compartilhar também recursos, atividades econômicas e atratividade 


\section{SÃO PAULO15 17 LISBOA $25 \sim 26$ JUN 2020}

política/eleitoral. A realidade brasileira questiona esse instrumento diretamente. $E$, inclusive, a participação social nesse formato fica cada vez mais inacessível.

Não obstante, o capítulo 3 da lei prevê a instituição da governança interfederativa, a qual, embora estabeleça princípios que garantem a autonomia dos entes federativos, possui um texto que não estabelece e estimula a gestão participativa. Um tanto contraditório, quando se coloca a autonomia do poder público contrapondo a garantia da participação e controle social pela sociedade civil organizada.

Falar dos instrumentos previstos no EM é falar sobre a inevitável similaridade com relação aos estabelecidos no EC, mas em uma nova escala. Mesmo que com nomenclaturas e escopos obviamente distintos, é inevitável a comparação quando se fala em plano de desenvolvimento urbano integrado; planos setoriais interfederativos; fundos públicos; operações urbanas consorciadas interfederativas; zonas para aplicação compartilhada dos instrumentos urbanísticos; consórcios públicos; convênios de cooperação; contratos de gestão; compensação por serviços ambientais ou outros serviços prestados pelo Município à unidade territorial urbana; parcerias público-privadas interfederativas etc. Para todos os teóricos que falam sobre a privatização das cidades, e o envolvimento nocivo de agentes públicos e privados, certamente teremos novos exemplos, em novas escalas.

Por fim, sobre a lógica financeira. Cabe registrar que referente que todas as perspectivas orçamentárias estão de acordo com a lei de responsabilidade fiscal do município, e deverão estar de acordo com os PPAs, LDOs e LOAs dos municípios integrantes da unidade territorial urbana, bem como dos estados aos quais estão inseridos. Entretanto, o mais grave é que o EM nasce com os artigos 17 e 18 do capítulo V, vetados. Os mesmos versavam sobre a construção de um Fundo Nacional de Desenvolvimento Integrado, estimulando e obrigando a União a investir em toda essa importante gestão interfederativa que já nasce sem qualquer repasse ou recurso assegurado para investir no desenvolvimento urbano integrado.

\section{Os "limites" da gestão metropolitana no Estatuto da Metrópole: Uma preocupante conclusão}

Acredita-se, nesse ensaio, que existem limites objetivos com o estatuto da metrópole, a considerar: i) limites escalares; ii) limites políticos-administrativos; iii) limites econômicos-sociais; e iv) limites referenciais. Para desenvolver a ideia aqui colocada pelos autores, inclusive, organizamos na gramática nossa linha de pensamento. De fato, o substantivo masculino "limite" revela uma epistemologia bastante interessante e metafórica com o tema.

Primeiramente, o limite pode ser entendido como sendo uma linha que, real ou imaginária, delimita e separa um território de outro (é uma fronteira). Daí a explicação sobre os limites escalares. Afinal, de que escala trata-se o estatuto da metrópole? No item 2 desse ensaio fica clara essa situação e, de fato, a metrópole do ponto de vista conceitual é muito perceptível, mas do ponto de vista prático é, como já mencionado, uma formação de grandes áreas e redes urbanas, de limites geográficos, demográficos, sociais e econômicos pouco precisos.

Por outro lado, limite pode ser entendido também como extensão ou relação temporal ou, ainda, em uma situação relacional ("até quando/onde é o seu limite"?). E daí é importante perguntar sobre a que tempo se pretende, e com quais agentes se pretende, formular uma política integrada e continuada? Políticos e 


\section{SÃO PAULO15 17 LISBOA $25 \sim 26$ JUN 2020

gestores mudam o tempo inteiro em nível estadual, e em tempos diferentes em nível municipal. E quando se fala que mudam, não mudam apenas na lógica democrática eleitoral, mas sim de perspectivas, alianças, vontades, interesses etc. $O$ corpo político é muito volátil, e as leis não conseguem estabelecer nenhum critério eficiente e eficaz de continuidade gestora. Se as atuais gestões não conseguem hoje partilhar pensamentos, como partilharão outras gestões futuras? Engana-se quem acredita em política urbana (ou geral) continuada. O Brasil, inclusive, demonstra a total descontinuidade de políticas nessa ordem. Vide, por exemplo, o atual cenário nacional de desarticulação de Conselhos e Conferências das cidades (e do próprio Ministério das Cidades), iniciados desde o EC de 2001, e desarticulados inicialmente em 2016, com um estrangulamento financeiro de suas realizações, e consolidados em 2019, com a extinção dos mesmos. Daí a afirmação dos limites políticos e administrativos do Estatuto das Metrópoles.

Um dos melhores conceitos sobre limite, sem sombra de dúvidas, é o que vem a partir da matemática. Para essa importante área lógica e racional, limite acaba sendo um valor determinado e fixo a partir do qual uma grandeza variável consegue se aproximar, mas nunca poderá atingir. Sim, esse é o caso metafórico perfeito para as problemáticas urbanas, em níveis metropolitanos. Os efeitos desiguais e segregatícios de cidades como São Paulo, Rio de Janeiro, Brasília, Belo Horizonte, Salvador etc., são percebidos no plano dessas cidades, mas transpassam os seus limites, e atingem cidades em seu entorno de maneira inevitável. $O$ trânsito nos grandes centros se inicia nas estradas e rodovias que ligam cidades desprovidas de serviços e comércios, e que buscam por isso todos os dias. Os problemas habitacionais consistem num alto valor do solo nos grandes centros, que acumulam uma habitabilidade periférica que atinge as demais cidades. O rio que cruza os grandes centros urbanos também passa pelas demais cidades do entorno. Os problemas de água e abastecimento energético são comuns. O que queremos demonstrar é que há uma problemática metropolitana consolidada nessas regiões, e aí vem os limites matemáticos. Quem pagará a conta? Qual cidade, de fato, irá disponibilizar recursos para desenvolver soluções urbanas "e integradas" em outro município?

E, por fim, chega-se ao conceito de limite a partir de um sinônimo, o de exaustão. Infelizmente, esse limite conclui esse trabalho a partir de uma observação muito preocupante em relação às cidades e metrópoles brasileiras. Inevitavelmente, a leitura desse ensaio possa vir a parecer pessimista, mas não o é. Chega-se ao limite, a partir da ideia de exaustão, a partir da percepção da construção referencial desse estatuto. As referências são importantes e grandes em palavras, mas fracas em ação. O Estatuto da Cidade consolidou uma relação urbana de privatização e valorização do solo urbano, em detrimento de uma real política de combate à exclusão e a segregação social e espacial nas cidades. Não falta bibliografia de importantes teóricos que desmistificam a real aplicabilidade dos instrumentos das políticas urbanas, ou dos que demonstram o quanto o solo urbano valorizou nas grandes cidades e, consequentemente, desencadeou todo um processo segregatício. Soma-se a isso o grande endividamento público, e os exorbitantes lucros de empreiteiras (nacionais e multinacionais) na execução de obras públicas. Ou seja, o investimento é público e o benefício, em geral, é privado. Num plano metropolitano, pontes, ferrovias, linhas de trem, redes de energia, e outras grandes obras de engenharia certamente prestigiarão a mesma lógica. Ou seja, a referência já é um limite por si só.

De fato, acredita-se que os Estatutos, seja da Cidade, seja da Metrópole, precisam descentralizar a última manifestação ainda não consolidada, o poder. Mas não o poder entre os agentes públicos, mas o poder dos agentes públicos em detrimento dos segmentos populares e sociais. Acreditamos que os atores da cidade precisam dirigir qualquer velho, ou novo, estatuto (e ter subsídios políticos, técnicos, jurídicos e financeiros), 


\section{SÃO PAULO15 17 LISBOA $25 \sim 26$ JUN 2020}

e não os velhos agentes políticos e econômicos de sempre. Ou isso, ou, de fato, esse ensaio apresenta uma posição pessimista sobre os limitados desdobramentos do Estatuto da Metrópole. Se já existe uma (in)governança municipal com o Estatuto da Cidade, não é um absurdo entender que desenvolveremos uma (in)governança metropolitana com o Estatuto da Metrópole. Por fim, registra-se que esse artigo faz parte de um conjunto progressivo de publicações sobre o tema, principalmente pelo atual estágio de desenvolvimento de estudos de caso e pesquisas sobre a questão levantada.

\section{Bibliografia}

ASCHER, F. (2001). "Metropolização e transformação dos centros das cidades". In: ALMEIDA, M. A. R. (ap.). Os centros das metrópoles: reflexões e propostas para a cidade democrática do Século XXI. São Paulo: Editora Terceiro Nome: Viva o Centro; Imprensa Oficial do Estado.

BRASIL. Lei Federal o⒔089 - Estatuto da Metrópole. Brasília, 12 de Janeiro de 2015.

CORRÊA, R. L. (1989). O Espaço Urbano. São Paulo, Ática.

DINIZ, E. (1995). "Governabilidade, Democracia e Reforma do Estado: Os Desafios da Construção de uma Nova Ordem no Brasil nos Anos 90". Dados, vol. 38, no 3. 1995.

IBGE - Instituto Brasileiro de Geografia e Estatística. Pesquisa de Regiões Metropolitanas, Aglomerações Urbanas e Regiões Integradas de Desenvolvimento. Divulgação semestral 2019.1. Disponível em https://www.ibge.gov.br/geociencias/organizacao-do-territorio/divisao-regional/18354-regioes-metropolitanasaglomeracoes-urbanas-e-regioes-integradas-de-desenvolvimento.html?=\&t=0-que-e, acessado em 04 de Fevereiro de 2020.

SOARES, P. R R. (2018). Metropolização, aglomerações urbano-industriais e desenvolvimento regional no sul do Brasil. Caderno Metrópoles, São Paulo, v.20, n.41, pp 15-34, jan/abr.

REIS, F. W. (1989). "Estado, Economia, Ética, Interesses: Para a Construção Democrática do Brasil". Planejamento e Políticas Públicas, vol. 1, oํ 1, junho.

"Governabilidade, Instituições e Partidos". Novos Estudos Cebrap, № 41, março/1995.

VELTZ, P. (1996). Mundialización, ciudades y territorios. La economía de archipiélago. Barcelona, Ariel. 